\title{
The unmet need of information access for family members of ICU patients
}

\author{
Christopher E. Cox ${ }^{*}$ and Hanne I. Jensen
}

C 2016 Springer-Verlag Berlin Heidelberg and ESICM

\section{Dear Editor,}

Information is critical to the success of clinical interactions among parties that may possess different abilities, levels of medical comprehension, and preparedness to take action. A substantial body of research has examined the process of information exchange (e.g., communication, incorporation of patient-reported outcomes measures in workflows, etc.) between clinicians and patients/ families, and its impact on both processes and outcomes in the context of critical illness. Perhaps less well explored is information access, a topic taken on by Mistraletti et al. in a recent issue of Intensive Care Medicine [1].

Think about a decision you made today. Maybe you browsed an online retailer to find an obscure type of lightbulb that fits your ceiling fan (the really tall one that needs the ladder). Of the 10 varieties of lightbulbs you reviewed, what drove you to choose the one you did? Perhaps it was the numerous five-star ratings provided by previous customers. Or the comparatively affordable price? Or the knowledge that it would arrive in 2 days or less, compared to longer wait times for cheaper brands? Regardless of the depth of your research, you have to admit that your access to trustworthy information made all the difference.

We would venture that few patients and families today possess a working knowledge of complex critical illness adequate to enable them to feel particularly confident in their roles as decision-makers, advocates, or partners in care $[2,3]$. Clinicians certainly want to help, but they are often overwhelmed with multiple patient care issues, note writing, billing, teaching, etc.- - time is short for deep daily conversations. Friends and family may not have ever encountered such a serious situation. The Internet is always open-what about that? Just try and you'll be

*Correspondence: christopher.cox@duke.edu

Duke University, Durham, CA, USA discouraged [4]. There is little curation of medical information relevant to critical illness, absolute uncertainty regarding trustworthiness, intimidating amounts of jargon, and a dearth of information for those who speak languages other than English, French, and German. There are no systems that easily facilitate an understanding of how others "like me" made decisions-or what the outcomes were. Few "question coaches" exist as well to help families learn to speak the acronym-overloaded language of medicine. And currently there is little practical application of data from either patients' health status or their family members' in-the-moment needs.

To truly personalize the experience and empower patients/families, we believe more attention needs to be given to information access, information sharing, and information infrastructure (Fig. 1) [5, 6]. Rapid, free access to essential information is the least we can aspire to provide as citizens and healthcare providers [8]. And this works both ways: clinicians should design and use systems that allow patients/families to provide information that is relevant to care and important to them. Such information sharing of course requires digital infrastructure that is currently painfully underdeveloped. The previous healthcare information technology charge in the USA was the "meaningful use" of health data. There is a new pivot toward interoperability of health system data as a path toward data empowerment, scalability, and unified learning health systems [9]. While both the USA and Denmark struggle to overcome the siloed and secretive nature of historically uncooperative electronic health record (EHR) vendors, other nations have done better such as the UK's ICNARC group.

But of course this digital infrastructure also includes the public domain. Mistraletti et al. have provided an important service to ICU families with their critical illness-centric brochure and informational website (www. intensiva.it) [10]. The aim of both the brochure and the

\section{Springer}




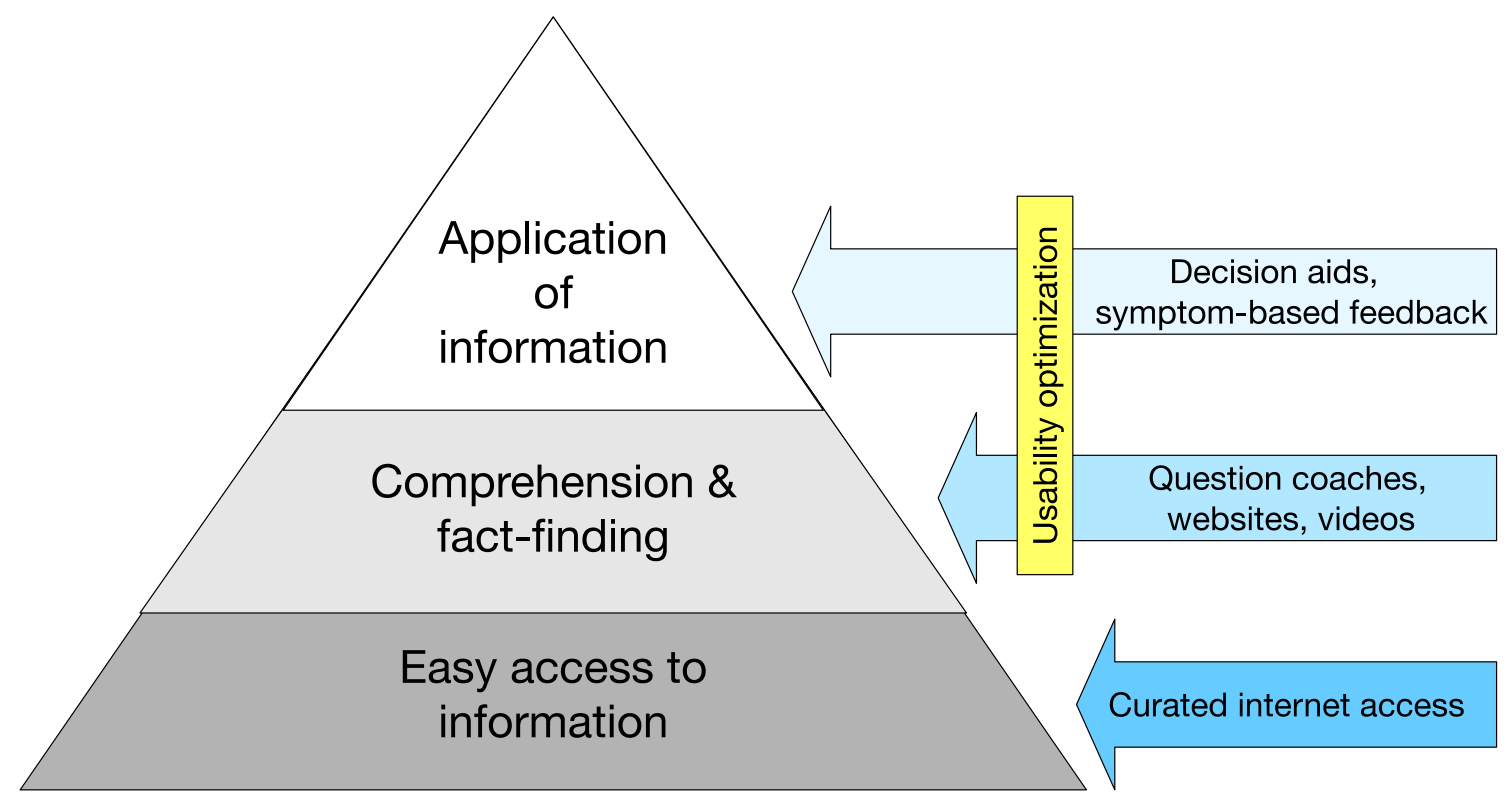

Fig. 1 Stages of information utilization in clinical settings. Examples of methods to enhance each step for patient/family user experience are shown in arrows. Loosely adapted from Longo et al. [7]

website was to combine a rational understanding of the ICU environment (explaining what happens, procedures, equipment, staff, timing and rules), with emotional justification (underlining that it is normal to experience doubt, anger, worry, apprehension, and suffering). In their before/after trial, these researchers found that a brochure and access to a complementary website were associated with improved prognostic understanding, awareness of procedures, and post-traumatic stress disorder symptoms. However, even though $73 \%$ stated that they had received the brochure, only $19 \%$ reported having viewed the website [1]. Combined with the before-after design, caution should be taken in regard to causality.

But while the differential contribution of brochure and website to improved outcomes may be murky, we are impressed with their novel approach. The study elucidates that there is no dominant single model that fits all, and that providing a wide range of information options will increase the possibility of meeting the individual family member's needs. However, the proportion of families who reported viewing the website may well have been higher if they had been given a short introduction to the website, provided with the website address on a written card or, as the authors suggest themselves, the website was made visible via posters in the family waiting room. It could be stated that providing such online information should be a standard expectation of all institutions with reasonable resources, whether the information is selfproduced or borrowed from others.
We would remind others who enter the health IT space to focus not just on content but also to assess and optimize the usability of their digital tools [10]. This can help to ensure that users can not only access the information but efficiently use it for purposes they value. To avoid risk of confounding, researchers should consider using other study designs such as cluster-randomized trials, steppedwedge, interrupted time series, and others.

Yet this is exciting work that could help ICU families to better understand what is going on in the ICU and to become better decision-makers-and experience better psychological outcomes in addition.

Received: 18 November 2016 Accepted: 16 December 2016 Published online: 23 December 2016

\section{References}

1. Mistraletti G, Umbrello M, Mantovani ES, Moroni B, Formenti P, Spanu P, Anania A, Andrighi E, Di Carlo A, Martinetti F, Vecchi I, Palo A, Pinna C, Russo R, Francesconi S, Valdambrini F, Ferretti E, Radeschi G, Bosco E, Malacarne P, lapichino G, The http://www.intensiva.it Investigators (2016) A family information brochure and dedicated website to improve the ICU experience for patients' relatives: an Italian multicenter before-and-after study. Intensive Care Med. doi:10.1007/s00134-016-4592-0

2. Azoulay E, Chevret S, Leleu G, Pochard F, Barboteu M, Adrie C, Canoui P, Le Gall JR, Schlemmer B (2000) Half the families of intensive care unit patients experience inadequate communication with physicians. Crit Care Med 28:3044-3049

3. Cox CE, Martinu T, Sathy SJ, Clay AS, Chia J, Gray AL, Olsen MK, Govert JA, Carson SS, Tulsky JA (2009) Expectations and outcomes of prolonged 
mechanical ventilation. Crit Care Med 37:2888-2894; quiz 2904. doi:10.1097/CCM.0b013e3181ab86ed

4. Mitchell IA, Schuster AL, Lynch T, Smith KC, Bridges JF, Aslakson RA (2015) Why don't end-of-life conversations go viral? A review of videos on YouTube. BMJ Support Palliat Care. doi:10.1136/bmjspcare-2014-000805

5. Cox CE, White DB, Abernethy AP (2014) A universal decision support system. Addressing the decision-making needs of patients, families, and clinicians in the setting of critical illness. Am J Respir Crit Care Med 190:366-373

6. Brown SM, Bell SK, Roche SD, Dente E, Mueller A, Kim TE, O'Reilly K, Lee BS, Sands K, Talmor D (2016) Preferences of current and potential patients and family members regarding implementation of electronic communication portals in intensive care units. Ann Am Thorac Soc 13:391-400

7. Longo DR, Woolf SH (2014) Rethinking the information priorities of patients. JAMA 311:1857-1858
8. Krumholz HM, Terry SF, Waldstreicher J (2016) Data acquisition, curation, and use for a continuously learning health system. JAMA 316:1669-1670

9. Office of the National Coordinator for Health Information Technology (2016) Connecting health and care for the nation: a shared nationwide interoperability roadmap. Available at: https://www.healthit.gov/sites/ default/files/hie-interoperability/nationwide-interoperability-roadmapfinal-version-1.0.pdf. Accessed 1 Dec 2016

10. Usability.gov (2016) Research-based web design and usability guidelines. Available at: http://www.usability.gov/sites/default/files/documents/ guidelines_book.pdf?post=yes. Accessed 1 Dec 2016 